\title{
Compliance with the guidelines of prescription writing in a central hospital in the West Bank
}

\author{
Y.I. Tayem, ${ }^{1}$ M.A. Ibrahim, ${ }^{1}$ M.M. Qubaja, ${ }^{1,2}$ R.K. Shraim, ${ }^{1,2}$ O.B. Taha ${ }^{7}$ and E. Abu Shkhedem ${ }^{1}$
}

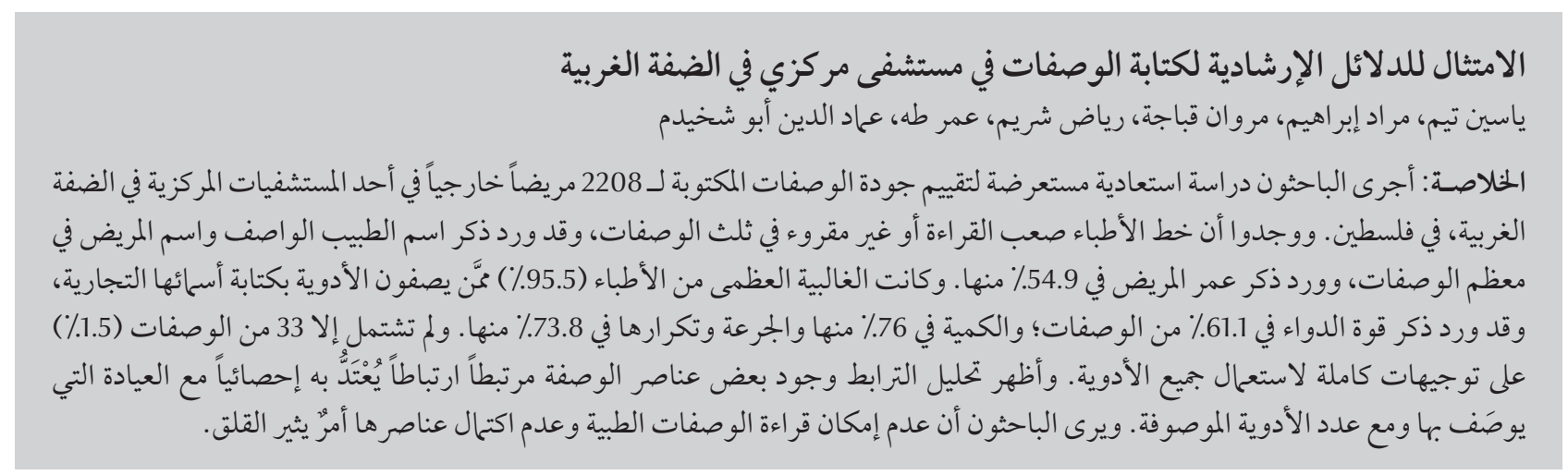

ABSTRACT This retrospective, cross-sectional study was carried out to evaluate the quality of 2208 outpatient prescriptions in a central hospital in the West Bank, Palestine. The physicians' handwriting was poorly readable or illegible in one-third of the prescriptions. The prescriber's name and signature and patient's name were mentioned in almost all orders whereas the patient's age was stated in $54.9 \%$. The vast majority of physicians (95.5\%) prescribed drugs using their trade (brand) names. Drug strength, quantity and dose/frequency were stated in $61.1 \%, 76 \%$ and $73.8 \%$ of prescriptions respectively. Only 33 prescriptions (1.5\%) contained full directions for use for all drugs. Correlation analysis revealed that the presence of certain prescription elements was statistically significantly associated with the clinic of origin and the number of drugs prescribed. The overall poor legibility and incompleteness of the prescriptions is of concern.

\section{Respect des recommandations de rédaction d'ordonnance dans un hôpital central de Cisjordanie}

RÉSUMÉ La présente étude rétrospective et transversale a été menée pour évaluer la qualité de 2208 ordonnances rédigées en consultation externe dans un hôpital central de Cisjordanie (Palestine). L'écriture des médecins était difficile à lire, voire illisible dans un tiers des cas. Le nom du médecin prescripteur, sa signature et le nom du patient étaient mentionnés sur presque toutes les ordonnances mais l'âge du patient n'était précisé que dans $54,9 \%$ des cas. La grande majorité des médecins (95,5\%) avaient prescrit des médicaments en utilisant leur nom commercial (de marque). La concentration, la quantité, la posologie/la fréquence étaient indiquées dans 61,1\%, $76 \%$ et 73,8 \% des ordonnances, respectivement. Seules 33 ordonnances (1,5\%) donnaient des instructions complètes pour la prise de tous les médicaments prescrits. Une analyse de la corrélation a révélé que la présence de certains éléments de prescription était associée de manière statistiquement significative au centre de santé à l'origine de l'ordonnance et au nombre de médicaments prescrits. La mauvaise lisibilité globale et le caractère incomplet des ordonnances sont préoccupants.

'Faculty ofMedicine, Al-Quds University, Abu Dis, West Bank, Palestine (Correspondence to Y.I. Tayem: yasin.tayem@gmail.com). ${ }^{2}$ Department of Pathology, Beit Jala Hospital, Bethlehem, West Bank, Palestine.

Received: 14/05/12; accepted: 07/08/12 


\section{Introduction}

Most medical consultations culminate in writing a prescription. This order from the physician to the dispenser is considered a medico-legal document, so it must be written clearly, accurately and completely to avoid potentially preventable but serious prescription errors, which are frequent causes of morbidity and mortality $[1,2]$. Several factors account for the increased incidence of prescription errors including, but not limited to, illegible prescriber's handwriting [3], increased number of drugs in a prescription [4] and irrational prescribing habits [5]. These errors can result in an increase in the number of adverse drug events, inappropriate or unsafe treatment, prolongation of illness or hospital stay and escalation of healthcare expenditure [6]. Dormann et al. reported that adverse drug reactions were the reason for $6 \%$ of hospital admissions and $4.2 \%$ of readmissions in Germany, causing additional cost of several hundred million euros [7]. Since good quality prescriptions comprise the main factor for minimizing dispensing errors, physicians should adhere to guidelines for prescription writing to ensure patient safety [8].

The drug prescription and administration process in most hospitals worldwide is still based on handwritten medical chart entries [9]. Several steps in this complex and unchecked process can engender a high number of relevant errors which may be a significant source of adverse drug events [10]. Certain elements must be written legibly, accurately and completely on the prescription order; these include the physician's name, address, telephone number and signature, as well as the patient's name, address, age, weight (especially in children and the elderly), and the date of the prescription, drug name (preferably generic), formulation, strength, dose, frequency of administration, quantity, reason for prescribing and directions for use in the patient's language [11]. The illegibility, incompleteness, or omission of any of these elements could result in misinterpretation of the prescription by the dispenser, and may lead to potentially serious prescription errors [1].

Because the art of prescriptionwriting is not sufficiently addressed in undergraduate medical education [12], many physicians do not have appropriate prescription-writing skills. As a result, the need to promote the acquisition of the proper skills in medical undergraduates has been highlighted [13]. Moreover, the prescribing habits of physicians working in health institutions should be assessed periodically to identify any defects and introduce corrective measures such as educational programmes on rational prescribing, followed by reminders and feedback to assess the physicians' response [14].

The major objective of this study was to evaluate the quality of prescriptions ordered by physicians in outpatient clinics and emergency rooms in a central hospital in the West Bank. In particular, we assessed the presence of the essential elements related to the prescriber, the patient and the main body of the prescription. We speculate that the results of this study will guide intervention programmes focusing on physicians working at health facilities to improve the quality of medical prescriptions in Palestine.

\section{Methods}

This study was carried out in Beit Jala hospital, the central governmental hospital in Bethlehem district, which has a population of 140000 , making up $7.3 \%$ of the population of the West Bank. Emergency room and outpatient prescriptions, irrespective of the clinic of origin, received and kept by the pharmacy department during the period 20 December 2010-19 December 2011 were analysed systemically and retrospectively. This period was divided into 4 seasons: winter, spring, summer and autumn. In each season, all prescriptions from 1 randomly selected week (7 working days) were analysed systemically. Analysis was carried out from January to March 2012.

Prescriptions were assessed for the presence of the essential elements which should be present in the order. Compliance with these elements was judged by the degree to which physicians had met the obligations of all the elements in the prescription order according to the World Health Organization (WHO) guidelines which are the official guidelines in Palestine [15]. A prescription element was labelled partially readable if it was partly legible and unreadable if none of the investigators present in that analysis session could read it. Instructions for drug use were partial if they were mentioned either partly or fully for some drugs on the prescription or full if they were fully mentioned for all drugs on the prescription.

Ethical approval for this study was provided by Al-Quds University Human Research Ethics Committee, West Bank, Palestine. Physicians in the target hospital were not aware that the study was being carried out.

\section{Statistical analysis}

Data generated were fed into SPSS, version 17 and simple descriptive statistics were utilized to analyse the results. The statistical significance was set at $P<0.05$. Pearson's correlation coefficient analysis was quoted to reflect the magnitude of association.

\section{Results}

Our sample comprised 2208 prescription orders. The majority of the prescriptions were issued from the outpatient clinics (90.3\%), followed by the emergency room $(7.8 \%)$; in the rest $(1.9 \%)$ the source was missing. The number of drugs included in the prescriptions ranged from $1-9$ but the majority (90.4\%) contained $\leq 3$ drugs. 
The distribution of the prescriptions over the seasons was: winter (30.6\%), spring (17.5\%), summer (35.6\%) and autumn (16.3\%). According to clinic of origin, $30.4 \%$ of the prescriptions were sent by the oncology clinic, followed by medicine (21\%), orthopaedics (9.5\%), surgery (9\%), ER (7.8\%), paediatrics (6.6\%) and obstetrics/gynaecology (6.3\%).

The handwriting of the prescribing physician was partially readable in $28.5 \%$ and illegible in $4.2 \%$ of the prescriptions. (Table 1), the prescriber's name and signature were present in $96.2 \%$ and $99.8 \%$ of the orders, respectively. However, all prescriptions were deficient in the prescriber's address and telephone number. Patient's name was present in all orders, whereas patient's age was present in only $45.1 \%$. None of the prescriptions included the patient's address, telephone number or weight.

Minority of drugs were prescribed using their generic names (3.2\%), brand names were utilized in $95.5 \%$, while the rest contained both names (1.3\%) (Table 2). The date of the prescription was mentioned in almost all orders (99.4\%). With regard to the main body of prescription (Table 2), drug strength, was mentioned for all drugs in $61.1 \%$, included for some drugs in $22.7 \%$ and was missing in the rest $(16.2 \%)$. The dose and frequency of administration were mentioned for all drugs in $73.8 \%$, mentioned for some drugs in $14.9 \%$ and not mentioned for all drugs in $11.3 \%$. Less than two thirds of the prescriptions contained the quantity that the pharmacist should dispense for all drugs, 15\% for some drugs and in the remainder (9\%) this element was missing. The instructions for patient's use were not mentioned for all drugs in the majority of the prescriptions (94.3\%), were partial in $4.2 \%$ and were full in only (1.5\%). Lastly, the patient's diagnosis was missing in $34.6 \%$ of the prescriptions.

Pearson's correlation coefficient was utilized to identify the factors that affected physician's adherence with the guidelines of prescription writing. The clinic of origin was strongly correlated with the presence of patient's age $(P<0.001)$, drug's strength $(P<$ $0.001)$, dose/frequency $(P<0.001)$ and directions for drug's use $(P<0.001)$. However, the number of drugs prescribed was significantly associated with mentioning patient's age $(P<0.001)$, drug's strength $(P<0.05)$, and dose/ frequency $(P<0.05)$.

\section{Discussion}

By and large, our results revealed a high rate of noncompliance with the recommendations for prescription writing provided by the WHO which could lead to serious errors in both dispensation and drug use [15].

The vast majority of orders contained $\leq 3$ drugs, indicating that the prescribing physicians had little tendency towards polypharmacy.

Almost all the prescriptions were dated but the patient's diagnosis was missing in $34.6 \%$. Almost one-third of the prescriptions were rated as partially readable or illegible. In comparison, in a study from a central hospital in Saudi Arabia, $35.7 \%$ of outpatient prescriptions were dated, the diagnosis was mentioned in $84.9 \%$ and almost twothirds were poorly legible [16]. The lege ibility of prescriptions in our study was far better than that reported in studies in Sudan (15.8\%) [17] and Ethiopia (15\%) [18]. Poor legibility and illegibility are serious deficiencies since they increase the risk of misinterpretation of the information by the dispenser and increase the likelihood of serious dispensing errors [9].

None of the prescriptions we examined contained the prescriber's address or telephone number. Sawalha et al. showed that, in private practice in the West Bank, these details were present on all prescriptions [19]. However, almost all the prescriptions in our study had the prescriber's name and signature; this is consistent with the findings from a study in a teaching hospital in Nigeria where the prescriber's name was mentioned on $80 \%$ of prescriptions and the physician's signature was present on $96 \%$ [20]. In a study from Sudan, in contrast, the physician's name was mentioned in only $6.7 \%$ of prescriptions [21]. These details are essential elements and can be used if further contact with the prescriber is needed by the dispenser for any clarification.

Almost all prescriptions contained the patient's name but age was mentioned in less than half. None of the prescriptions stated the patient's contact information or weight. In a study from Nigeria, almost all prescriptions were deficient in patient's address but,

\begin{tabular}{lcc}
\hline $\begin{array}{l}\text { Table 1 Analysis of identifying information for patients and prescribers on } 2208 \\
\text { prescriptions ordered by outpatient clinics and emergency rooms at a central } \\
\text { hospital in the West Bank }\end{array}$ & No. \\
\hline Element & 2124 & 96.2 \\
Prescriber's information & 2203 & 99.8 \\
Name & 0 & 0 \\
Signature & 0 & 0 \\
Address & & \\
Tel number & 2207 & 100.0 \\
Patient's information & 1212 & 54.9 \\
Name & 0 & 0 \\
Age & 0 & 0 \\
Address & & $\%$ \\
Telephone number & & \\
\hline
\end{tabular}




\begin{tabular}{|c|c|c|}
\hline Element & No. & $\%$ \\
\hline \multicolumn{3}{|l|}{ Prescription date } \\
\hline Mentioned & 2195 & 99.4 \\
\hline Not mentioned & 13 & 0.6 \\
\hline \multicolumn{3}{|l|}{ Drug name } \\
\hline Generic & 71 & 3.2 \\
\hline Trade (brand) & 2109 & 95.5 \\
\hline Mixed & 28 & 1.3 \\
\hline \multicolumn{3}{|l|}{ Drug strength } \\
\hline Mentioned for all drugs & 1349 & 61.1 \\
\hline Mentioned for some drugs & 501 & 22.7 \\
\hline Not mentioned for all drugs & 358 & 16.2 \\
\hline \multicolumn{3}{|l|}{ Drug's dose units } \\
\hline Mentioned for all drugs & 1630 & 73.8 \\
\hline Mentioned for some drugs & 328 & 14.9 \\
\hline Not mentioned for all drugs & 250 & 11.3 \\
\hline \multicolumn{3}{|l|}{ Drug's quantity } \\
\hline Mentioned for all drugs & 1677 & 76 \\
\hline Mentioned for some drugs & 332 & 15 \\
\hline Not mentioned for all drugs & 199 & 9 \\
\hline \multicolumn{3}{|l|}{ Patient's instructions } \\
\hline Full & 33 & 1.5 \\
\hline Partial & 92 & 4.2 \\
\hline Missing for all drugs & 2083 & 94.3 \\
\hline \multicolumn{3}{|l|}{ Diagnosis } \\
\hline Mentioned & 1444 & 65.4 \\
\hline Not mentioned & 764 & 34.6 \\
\hline \multicolumn{3}{|l|}{ Prescriber's handwriting } \\
\hline Unreadable & 93 & 4.2 \\
\hline Partially readable & 630 & 28.5 \\
\hline Readable & 1485 & 67.3 \\
\hline
\end{tabular}

in contrast to our results, almost all contained the patient's age [20]. In another Sudanese hospital study, the patient's full name was mentioned in $18.8 \%$ of prescriptions only [21]. In a 2010 study in the private health sector in the West Bank, less than half of the orders contained patient's age [19]. The omission of patient's weight increases errors in drug dosing, especially at age extremes. Similarly, lack of patient's contact information is also serious when problems in the prescription are discovered after dispensing and the dispenser needs to contact the patient to correct the problem.
The vast majority (95.5) of the drugs on the prescriptions we examined were ordered by their brand names. Similarly, in a hospital study conducted in Brazil, in $89 \%$ of prescriptions, brand names were utilized [22]. In a Sudanese study, however, $19.5 \%$ of drugs were prescribed by their generic names [17] and a similar figure was reported in a study from Saudi Arabia [16]. In the private sector in Palestine, only brand names were used in a study carried out in Nablus [19]. The use of generic names is recommended by the $\mathrm{WHO}$ and regarded as an important factor for promoting rational use of drugs [15]. Furthermore, the use of generic names contributes to cost reduction and provides more alternatives for drug purchases [23].

The strength and dose/frequency of administration were complete in two-thirds of the prescriptions in our study and almost $61.1 \%$ of the orders indicated the quantity to be dispensed for all drugs. However, only $1.5 \%$ of the prescriptions contained full instructions for drug's use while $4.2 \%$ contained partial instructions. In a study from Saudi Arabia, drug strength and were mentioned in $26.6 \%$ and dosage units in $55.6 \%$ of prescriptions while only $6 \%$ of orders contained drug quantity [16]. In addition, only $2.3 \%$ of the prescriptions contained full direction for use [16]. In a study from Sudan, $43.8 \%$ of prescriptions were not accompanied by instructions to patients and 59.7\% lacked drug quantity [17]. In private practice in the West Bank, the strength was missing in over $70 \%$, while frequency and instructions for use were present in over $80 \%$ of prescriptions [19]. The considerable of lack of recommendations for use is worrisome since this information is an essential part of the prescription and should be written in a clear, objective, and accurate fashion. Such information can foster patient compliance with drug use, ensure safe use of medications and results in a fewer complications and adverse reactions.

This study has certain limitations which should be taken into consideration when interpreting the findings. First, prescriptions analysis was restricted to the outpatient setting while the inpatient situation remained unknown. Second, this investigation targeted a single hospital in the West Bank so the results may not be generalizable. A larger scale study targeting hospitals throughout the West Bank is needed to identify the true rates of adherence to rational prescription writing. 


\section{Conclusions}

In summary, a considerable proportion of prescriptions reviewed in this study suffered from serious deficiencies and were not properly written. The need for reinforcing physicians' awareness on the importance of adhering to the guidelines for prescription writing is obvious and follow-up on the matter is needed. Moreover, to minimize prescribing errors due to illegibility and incompleteness of prescriptions, we recommend updating the prescription form to include allitems recommended by the WHO, or utilizing computerized prescribing in governmental hospitals in the West Bank.

\section{Acknowledgements}

We express our appreciation to the administration and pharmacy staff at Beit Jala hospital for their cooperation with the investigators. The support of the Ministry of Health is also gratefully acknowledged.

Funding: None

Competing interests: None declared.

\section{References}

1. Meyer TA. Improving the quality of the order-writing process for inpatient orders and outpatient prescriptions. American Journal of Health-System Pharmacy, 2000, 57Suppl 4;S18-S22.

2. Wunsch MJ et al. Prescription drug fatalities among women in rural Virginia: a study of medical examiner cases. Journal of Opioid Management, 2009, 5:228-236.

3. Hartel MJ et al. High incidence of medication documentation errors in a Swiss university hospital due to the handwritten prescription process. BMC Health Services Research, 2011, 11:199.

4. Atanasova I, Terziivanov D. Investigation on antibiotics in a hospital for a one-year period. International Journal of Clinical Pharmacology and Therapeutics, 1995, 33:32-33.

5. Al Khaja KA et al. Rational use of antimicrobials in infants in primary care of Bahrain. Journal of Tropical Pediatrics, 2006, 52:390-393.

6. Blatt A, Chambon R, Lemardeley P. Forme légale et cout des prescriptions a l'Hôpital Central de Yaoundé, Cameroun [Legal format and costs of prescriptions at the Central Hospital in Yaounde, Cameroon]. Médecine tropicale : revue du corps de sante colonial, 1997, 57(1):37-40.

7. Dormann $\mathrm{H}$ et al. Readmissions and adverse drug reactions in internal medicine: the economic impact. Journal of Internal Medicine, 2004, 255:653-663.

8. Francois $\mathrm{P}$ et al. Evaluation of prescription-writing quality in a French university hospital. Clinical Performance and Quality Health Care, 1997, 5:111-111.

9. Bobb A et al. The epidemiology of prescribing errors: the potential impact of computerized prescriber order entry. Archives of Internal Medicine, 2004, 164:785-792.

10. Barber N, Rawlins M, Dean Franklin B. Reducing prescribing error: competence, control, and culture. Quality \& Safety in Health Care, 2003, 12(Suppl. 1):i29-i32.

11. Williams BR, Kim J. Medication use and prescribing considerations for elderly patients. Dental Clinics of North America, 2005, 49:411-427.

12. Avorn J. The prescription as final common pathway. International Journal of Technology Assessment in Health Care, 1995, 11:384-390.
13. Heaton A, Webb DJ, Maxwell SR. Undergraduate preparation for prescribing: the views of 2413 UK medical students and recent graduates. British Journal of Clinical Pharmacology, 2008, 66:128-134.

14. Qureshi NA et al. Effectiveness of three interventions on primary care physicians' medication prescribing in Riyadh City, Saudi Arabia. Eastern Mediterranean Health Journal, 2011, 17(2):172-179

15. De Vries TPGM et al. Guide to good prescribing: a practical mant ual. Geneva, World Health Organization, Action Programme on Essential Drugs, 1994 (WHO/DAP/94.11).

16. Irshaid YM et al. Compliance with good practice in prescription writing at outpatient clinics in Saudi Arabia. Eastern Mediterranean Health Journal, 2005, 11(5-6):922-928.

17. Yousif $\mathrm{E}$ et al. Deficiencies in medical prescriptions in a Sudanese hospital. Eastern Mediterranean Health Journal, 2006, 12(6):915-918.

18. Makonnen E, Yoseph M, Berhane Y. Quality of prescription at a tertiary care pharmacy in Addis Ababa. Ethiopian Medical Journal, 2002, 40:233-239.

19. Sawalha AF et al. Analysis of prescriptions dispensed at community pharmacies in Nablus, Palestine. Eastern Mediterranean Health Journal, 2010, 16(7):788-792.

20. Erhun WO et al. Legal issues in prescription writing: a study of two health institutions in Nigeria. International Journal of Pharmacy Practice, 2009, 17:189-193.

21. Yousif MA et al .Investigation of medication prescribing errors in Wad Medani, Gezira, Sudan. International Journal of Risk \& Safety in Medicine, 2011, 23:11-16.

22. Siqueira JS et al. Analysis of the quality of prescriptions at a cardiovascular ward in Brazil: a pilot study. International Journal of Clinical Pharmacology, Therapy and Toxicology, 2011, 33:260-263.

23. Ladue $L$ et al. Generic psychotropic medications: issues of cost-effectiveness and patient benefit. Southern Medical Journal, 2011, 104(10):711-714. 